\title{
Community Structure and the Status Attainment Process of the Jewish Population in Israel*
}

\author{
Vered Kraus \\ The University of Haifa \\ Department of Sociology \\ Haifa, Israel
}

\author{
Dov Weintraub \\ The Hebrew University \\ Department of Sociology \\ Jerusalem, Israel
}

\begin{abstract}
A b s t $\mathrm{r}$ a $\mathrm{ct}$ : This paper analyses how the national process of status attainment is in Israel mediated by interurban differences in opportunity structure. It is shown that while sociological literature is on the whole ambiguous in this respect, and presents no consistent picture, here the impact of community residence is clear and considerable. This impact is both additive and nonadditive, and affects status attainment in general as well as impinging differentially on different social groups - so that "ethno-ecological" patterns of attainment crystallize.
\end{abstract}

\section{Introduction}

A look at social stratification in general, and at status attainment in particular, through society's ecological variations has a long history, notably in American sociology. The oldest such tradition is undoubtedly the study of the rural-urban dimension, and it has well documented the differentials existing in this respect. More recent, but increasingly coming to the fore, are within-urban sector comparisons; there are numerous researches which adopt the city as their unit of analysis, and compare socioeconomic distributions and the process of status attainment in relation to community of residence.

In contrast to between-sector analysis, however, the evidence presented by inter-urban comparisons is conflicting and does not lend itself to a clear interpretation, either with regard to the very existence of urban differences in attainment, or in respect to their basis and direction. To be sure, most of the literature - theoretical and empirical - supports the view that a person's status attainment is perceptibly influenced by his community of residence. This has been observed, first of all, as regards the range and

* This paper is based on the study "The Opportunity Structure, Mobility, and Fertility in Israel", conducted by the Department of Sociology, the Hebrew University, jointly with the Brookdale Institute, Jerusalem, and with the cooperation of the Israel Central Bureau of Statistics. The data were collected with the help of a grant by the Population Council, which we gratefully acknowledge.

We are also grateful to Dr. Israel Adler and Professor Ozer Schild, who read an earlier version of the manuscript and offered many critical suggestions. level of achievement. Thus Blau and Duncan (1967) interpreted differences in mean socioeconomic status as indicative of differences in occupational opportunities which exist across cities, without, however, specifying precisely how this influence is articulated and effected. Hodge and Siegel (1968) and Rossi (1972) observed that it is reasonable to expect that the opportunity structure within which a person lives should have an impact on his achievements. More specifically, Duncan and Reiss (1956) and Schnore (1963) showed that the mean level of occupational status attainment is positively re. lated to city size, while Rogoff (1957) saw this factor as significant for the stratificational system as a whole, suggesting that different patterns of attainment are consequently bound to emerge in different urban settings. At the same time, attention was focused on differences in the structure of the attainment process, especially on its flexibility and openness. In their pioneering study, Hochbaum et al. (1955) thus compared a metropolitan and a small urban community and found that zero-order correlations among income, education and occupational status were lower in the former - reflecting the larger unit's greater flexibility and greater scope in enabling achievement along a variety of relatively independent tracks. In Hodge's later (1970) formulation, city size was found to be positively related to lack of status "crystallization" or rigidity: "Because such status variables are only loosely intertwined ... those with little education may still achieve ample income, and those with modest income may land a prestigeful job." In a like vein, Lane's work focused on the openness of status attainment or its universalism - as reflected in the extent to which 
occupational status depended on respondent's own educational achievement as against his father's occupational status. In her 1968 study of six American cities she showed that size has both additive and non-additive effects on this openness, while her more recent (1972) analysis traced the same effect to diversity of occupational structure, and pointed out that when this factor was controlled, the positive impact of urban size on status openness diminished. Theoretically the most cogent statement on both the nature of universalism of attainment, and on what precisely are the factors in opportunity structure which influence it, was made by Treiman (1970). And although his analysis related primarily to national stratification systems, it also includes the level of community of residence: "With increased industrialization, the influence of status of origin factors (father's occupation in particular) will decrease and the influence of education will increase -... As functional specialization increases along with the complexity of the division of labour, father's occupation will have less influence on his son's - because of increased bureaucratization of the work setting, and because the increased number of jobs and complexity of occupational structure will make it less likely, by chance alone, that the occupations be similar."

By contrast, however, Thernstrom (1964) found in his study on intergenerational mobility that mobility patterns may be expected to be comparable across different areas and localities in the U.S.A., because the social processes which give rise to them are essentially similar within the society. Mueller (1974), in a replication of Lane's 1972 study, but including fifteen larger cities and additional independent variables, found neither additive nor non-additive city effects on level and structure of attainment - concluding that "these findings for non-additivity are interpreted to mean that across U.S. communities the processes whereby socio-economic status is achieved are homogeneous." Finally, and most recently, Hauser and Featherman (1977), in reanalyzing Mueller's data in a first attempt to estimate urban effects on racial discrimination in status attainment, found only minor differences in this respect: "Racial discrimination does not decrease as a city size increases." Thus, the issue of community of residence affects on status attainment stays unre- solved, concerning both what underlies this contextual influence and what effects are to be expected; and there is need of further systematic study.

The area in which this need is most felt seems to be the reconceptualization and reoperationalization of urban opportunity structure. As was seen, most studies have defined this factor in terms of size differentials; and it is highly likely that it is the lack of sufficient discriminatory power of size alone which is responsible for much of the contradictory and ambiguous findings. However, even more comprehensive studies which use additional explanatory variables, do not take account of factors which were found to be of significance in the context of other urban research - such as city age, successfully used by Schnore (1963) in his analysis of metropolitan-suburban socio-economic differences; or population composition, spelled out in studies of urban order and quality of life; and outmigration. Also, the simultaneous use of, and lack of distinction between variables which relate to the actual contents of urban opportunity structure, such as occupational diversity, together with variables denoting general urban properties which determine or influence this structure, such as size - has made the formulation of a cogenial conceptual framework more difficult and caused effects to possibly cancel each other out empirically.

Another area - a substantive one - which needs further research and more definitive analysis, is the disaggregation of community effects on primordial groups, racial and others. Surely, that is an important issue, for it is the community effect which mediates the actual participation of such groups in the stratificational system. And yet, as was seen, there is only one study - presenting, moreover, no conclusive evidence on this effect.

That those two foci are important is in fact suggested by research carried out in Israel. In general, work on community of residence and stratificational processes has lagged in this country considerably behind the United States. True, analysis of the place and development of different communities in relation to nation building in general and immigrant absorption in particular, has been an important concern since in- 
dependence (Eisenstadt 1963; Cohen 1969; Berler 1970; Shahar et al. 1973). However, a systematic comparative perspective as well as a focus on status attainment has been lacking. Indeed, up till now only three such studies have been undertaken all in the late seventies - and even they have related primarily to additive effects. Interestingly enough, however, Israeli studies seem to have broken new ground, or adopted promising strategies precisely in those respects in which the much older American tradition has been weaker. They have stressed, first of all, the centrality of the primordial factor - in Israel's case ethnic - in the analysis of community effects. As is well known, Israel is a country of immigrants from a variety of geo-cultural backgrounds characterized by wide differences in traditions, level of modernization, and socio-economic resources; and it is committed to their full absorption and integration. Israel has thus faced from its very independence an ethnic problem of considerable magnitude and immediate salience; and Israeli sociologists were for many years in the vanguard of the study of ethnic stratification in general and ethnic integration in particular. Thus, even though the initial studies (cf. Eisenstadt 1953, 1956, 1967; Matras 1962, 1965; Lissak 1963, 1969; Weintraub 1965) were on the whole piecemeal, based on small samples, and commanded limited empirical evidence, they nevertheless very early in the game identified and documented ethnicity as the main source of social inequality in the Jewish community of the country. In particular, they recognized the crucial differences existing between those of "modern Western" - i.e. European and American - origin, and those of "traditional Oriental" - that is Asian and African one - perceiving those with Western background to be advantaged with respect to well-nigh all social and economic rewards, and those with Oriental background disadvantaged. These perceptions have been fully sustained in virtually all subsequent data describing such differences quantitatively; and the most recent findings show that there still exists differential access to education and occupational attainment within educational-origin and occupational-origin categories, as well as differential patterns of mobility which, if anything, broaden the gap (cf. Adler/Hodge 1976; Matras/Weintraub 1978a). And it is not strange, therefore, that the discriminatory effect of community of residence on this gap has been given pride of place.

Second, largely so as to meet this interest, a different strategy of defining and studying the urban opportunity structure has evolved. That is to say: since the focus has been primarily on pinpointing the ethnic stratification effect of community of residence, rather than on comparing systematically the impact of different opportuni. ty structure components through which this effect is articulated, the emphasis has been on identifying and analyzing distinct and significant community types or profiles as defined by general urban properties. To be sure, the issue of conceptualizing the various aspects of opportunity structure as well as the evaluation of the differential weight of specific factors has suffered. There is no doubt, however, that the findings obtained here have been clearer and more consistent than in the U.S.A.

In this way, Spilerman and Habib (1976) contrasted the "development town" type of community ${ }^{1}$ - characterized by being small, established after independence, settled in development regions, and populated mainly by new immigrants from Oriental backgrounds - with the aggregate of other cities, and found a considerable additive impact on ethnic stratification and on labor force characteristics. In a different dichotomy, Matras and Weintraub (1977b), in a study of ethnic differentials in intergenerational mobility, distinguished between the socioeconomic "center" of the country, comprising the veteran metropolitan centers of Jerusalem, Tel-Aviv and Haifa and all the cities and towns that are old established or have a majority of veteran population, and its urban "periphery", represented by new localities and those settled

1 A development town "proper" may be defined by three criteria:

a) Establishment after independence (1948).

b) Location in a development region (usually remote and underpopulated).

c) Population composed mainly of new immigrants, who came to the country after 1948 (cf. Berler 1970). However, settlements that have two out of three such features - namely (b) and (c), are also considered to belong to this category and to possess its essential characteristics.

Created primarily in order to meet the needs of population dispersion, and to prevent overcongestion and the possible smothering of veteran metropolitan areas, the development town program gave rise to 17 units between 1948 and 1960 . 
mainly by new immigrants. They found that the "periphery" is on the whole more disadvantaged relative to the "center", being lower in inherited and achieved status, having less mobility into the upper educational and occupational levels, and being characterized by a generally bigger intergenerational occupational gap. Also, the intergenerational ethnic dissimilarities are increased thereby, so that the factor of residence further contributes to the salience of the geocultural background in strata formation, and increases the divergence of ethnic groups. Finally, in a similar but more systematic way, Weintraub and Kraus (1977) arranged all urban communities in Israel by the geo-demographic criteria by which the nature of the local opportunity structure, in terms of economy, services and sociocultural horizons and drive, was assumed to be in a large measure determined. To wit: size, geographic location, length of existence, and composition of population ${ }^{2}$.

The impact of the major profiles emerging form the taxonomy was then analyzed in a twofold way $^{3}$ : First, their socio-economic contents were

2 A. Size - with distinction among (a) major urban centers, (b) middle-size cities, and (c) towns.

B. Geographic location - distinguishing among (a) in, or within easy commuting distance of, a major conurbation; (b) further from such conurbation, but within developed and populated areas; and (c) in underpopulated and underdeveloped ones.

C. Length of existence - whether (a) old-established, with a likely accumulation of institutional assets; or (b) newly founded and relatively deprived; in Israel, Independence - 1948 - is an obvious cutting point.

D. Basic "quality" or composition of population in terms of properly functioning, settled, active and relatively advantaged groups, or else those with limited assets, lesser participation and greater marginality. In Israel, 1948 again signifies whether the settlers are established veterans, as opposed to new immigrants. Accordingly, distinction was made among (a) localities that are populated mainly by veterans; (b) those that have a large veteran segment; and (c) those that are composed predominatly of newcomers. The help of Dr. Amiram Gonen of the Department of Geography of the Hebrew University in this classification is gratefully acknowledged.

3 Obviously, justice could not be done to the full range of variability obtained from the cartesian product of these dimensions, both because many groups would be too small for analysis and because in a country like Israel some of the possibilities do not exist. In consequence, the following profiles (which of necessity included borderline cases) were identified and related to:
A. The three metropolitan centers (Jerusalem, Tel-Aviv and Haifa) which are large, geographically central, have long existence, and mainly veteran population that is, ++++ .

B. Ten cities that are middle-sized, intermediate in location (i.e., in the populated and developed part of the country but not directly in any metropolitan catchment area), have long existence, and mainly veteran population, that is $\forall \forall$ ++ .

C. Three cities that are middle-sized, Intermediate in location as above (except for one city - Beer Sheva - which is in the distant and sparesely populated Southern Region. Because, however, it is the area's capital and main urban center, its geographical distance is compensated for by its special functions and weight), newly established and have a considerable segment of veteran settlers - that is, $\forall \forall$ - $\forall$.

D. Five cities that are small, intermediate in location, old-established, but also have only a large segment of veteran settlers - that is, $-\forall+\forall$.

E. Ten cities, that are small, intermediate in location (except for Eilat, Israel's Red Sea port which, though far from the central coast area, is itself of industrial, maritime and tourist importance and connected by convenient road and air transportation; and cannot, therefore, be properly considered as distant); newly established (except for Safed and Tiberias - which though of long standing, indeed historically ancient, constituted before Independence but very small Jewish communities within larger Arab populations, who left in 1948; so that their present population and development dates, in fact, since after that time); and have a large segment of veteran settlers, - that is, - $\forall-\forall$.

F. Eleven cities that are small, intermediate in location, newly established (strictly speaking, most of these cities existed before Independence, but as Arab cities; they became, in fact, abandoned after almost all of the original inhabitants left in 1948 and were re-established anew), and have a predominantly immigrant population - that is, $¥-\cdots$.

G. Eight cities that are small distant in location, newly established, and dominated by new immigrants - that is, -- --.

(Types $\mathrm{E}$ and $\mathrm{G}$ both belong to the "development town" category - see note 2 ; while $F$ is an "abandoned town" - one otherwise similar, but not placed in a development region).

The structure of the urban universe was thus as follows:

\begin{tabular}{ccccc}
\hline Profiles & Size & Location Age of City & $\begin{array}{l}\text { Status of } \\
\text { Settlers }\end{array}$ \\
\hline A & + & + & + & + \\
B & $\forall$ & $\forall$ & + & + \\
C & $\forall$ & $\forall$ & - & $\forall$ \\
D & - & $\forall$ & + & $\forall$ \\
E & - & $\forall$ & - & $\forall$ \\
F & - & $\forall$ & - & - \\
G & - & - & - & - \\
\hline
\end{tabular}


examined, and a considerable measure of correlation was established between them, and between the distribution of ethnicity, ascribed background, and achieved status, on the one hand, and processes of strata formation on the other. Then, the two polar types - profiles $\mathbf{A}$, as against profiles $\mathrm{E}, \mathrm{F}, \mathrm{G}$ - and representing two extreme configurations of local opportunity structure, or what may be termed the hub of the urban "center" vis-a-vis the hub of the urban "periphery", were isolated and contrasted ${ }^{4}$, documenting a considerable community-type impact on level of attainment in both overall as well as ethnic terms. This impact was maintained also with ethnic composition controlled.

The purpose of the present study, using the same data, status attainment variables, and the new strategy of ordering urban opportunity, structures, is to carry the analysis further along three lines: (a) To examine the net or non-additive effects of community of residence on the nature of the status attainment process - that is, whether there exists a differential process of attainment as a function of community configurations. This analysis will thus refine Israeli data and the available studies of flexibility and openness of attainment; (b) To examine more authoritatively the non-additive effects of the community on ethnic discrimination in the level of attainment; (c) And last but not least, to see whether community and ethnicity combine to produce distinct ethno-residential or ethno-ecological patterns of attainment, differing from the impact of each factor alone. This seems to us a novel perspective, reflecting a mechanism through which different groups differentially adjust to varying opportunity structures.

\section{Data, variables and presentation}

The data of the analysis - the same, as mentioned above, as in our previous research - are drawn from the national mobility study carried out in April-June $1974^{5}$. This study, combining the regular Labor Force survey of the Central

\footnotetext{
4 A pilot analysis having shown the differences between the top profile - A - and the middle ones $-B, C, D-$ not to be significant.
}

5 This is in fact Israel's first national mobility survey.
Bureau of Statistics with a special mobility questionnaire, included a sample of some 6000 persons aged 14 and over, Jewish and non-Jewish ${ }^{6}$. From this sample we utilized a sub-sample of Jewish employed males in the civilian labor force, aged $25-64$, living in the two extreme categories of urban community - with the inflated sub-population of the "center" totalling 115,704 , and of the "periphery" 35,829 .

\section{The analysis includes:}

(a) Three achieved status variables, namely respondent's education (RED), measured in terms of years of schooling completed; respondent's occupational status (ROS), measured in terms of a prestige score (for each 3 digit occupational census classification a prestige score, based on 3 digit Kraus prestige score, was assigned (Kraus 1976)); and respondent's income (RIN), measured in terms of annual income in Israeli pounds, available for wages and salaried employees only.

(b) Five antecendent variables are included: father's education (FED) in terms of type of school completed ${ }^{7}$; father's occupational status (FOS), measured in terms of a prestige score (for each 2 digit occupational census classifica-

6 Specifically, the survey has provided intra-generational mobility data for all persons aged 14 and over in some 6,000 households sampled, and intergenerational mobility data for heads of households and their wives. These are some 857,000 households in Israel, including 783,000 Jewish households (head of household is Jewish) and 74,000 non-Jewish ones. The inflated target population consists of an estimated $2,161,283$ persons aged 14 plus, including $1,911,526 \mathrm{Jews}$ and 249,757 non-Jews. The number of sample records in the survey sample is 15,078 including 11,917 Jews and 3,161 nonJews. The sampling procedure was identical to that of the ongoing Labor Force Survey and has been noted in Central Bureau of Statistics Publications.

7 We use here type of school, rather than years of schooling, as for the respondents themselves, since these latter are hard to obtain for abroad, and when obtained are very difficult to interpret because of the very large variety of educational systems covered. The types are as follows:

1. Completed no school.

2. Completed elementary school.

3. Completed Yeshiva (Jewish religious primary or post-primary school).

4. Completed secondary school.

5. Completed teachers' (or other post-secondary) seminar.

6. Completed university. 
tion, a prestige score, based on 2 digit Kraus prestige score, was assigned $)^{8}$; number of siblings (SIB), when the respondent was 14 years old; and continent of birth (CB) with two population groups distinguished: those born in EuropeAmerica, and Israeli born of European-American parents (EA); and those born in Asia-Africa, and Israeli born of Asian-African parents (AA). (Israeli born of Israeli parents were excluded, as they constitute only $3 \%$ of the population), and the age of the respondent, measured by year of birth (YB) ${ }^{9}$.

The presentation falls into four parts. First, the structure of status attainment as a function of "central" or "peripheral" community configuration is analyzed. Then, community configuration and ethnic discrimination are related. To

8 It was possible to code father's occuapation only at the 2 digit level of the 3 digit classification.

9 This variable was included in our analysis because the possibility the level of status attainment can be influenced by the number of years a person is exposed to labor force experience, in the analysis that follows we control for the year of birth. Thus, all the regression equations computed, include year of birth. round off the finding, ethno-residential patterns of attainment are examined. Finally, a discussion and some general conclusion are offered.

\section{Structure of status attainment as a function of community of residence}

Weintraub and Kraus (1977) have already shown that both inherited status and the level of socioeconomic achievements clearly reflect the nature of community of residence. However, for convenience's sake and so as to set the subsequent analysis in its context, this factor is briefly summarized.

Table 1 presents the mean achieved status for those residing in the "center" and in "periphery" by ethnic groups.

As can be seen, the achievements of those residing in the "center" are considerably higher: their mean years of schooling are about 11 as against 8 in the "periphery". Their mean prestige score is about $\mathbf{4 0}$ points on a hundred point scale, as opposed to about 25 ; and their mean annual income is about $19,000 \mathrm{IL}$, in comparison

TABLE 1 Means, standard deviations (in parenthesis), for employed males aged $25-64$ by type of community and ethnic groups

\begin{tabular}{lccc|ccc}
\hline & & & \multicolumn{3}{c}{ PERIPHERY } \\
\hline & Total & $\begin{array}{c}\text { European- } \\
\text { American }\end{array}$ & $\begin{array}{c}\text { Asian- } \\
\text { African }\end{array}$ & Total & $\begin{array}{c}\text { European- } \\
\text { American }\end{array}$ & $\begin{array}{c}\text { Asian- } \\
\text { African }\end{array}$ \\
\hline FED & 2.77 & 3.03 & 2.21 & 2.11 & 2.75 & 1.88 \\
& $(1.34)$ & $(1.37)$ & $(1.08)$ & $(1.17)$ & $(1.42)$ & $(0.98)$ \\
FOS & 34.96 & 37.15 & 30.20 & 27.47 & 32.64 & 25.56 \\
& $(23.29)$ & $(24.53)$ & $(19.52)$ & $(18.60)$ & $(22.17)$ & $(16.80)$ \\
SIB & 4.07 & 3.42 & 5.50 & 5.12 & 3.55 & 5.70 \\
& $(2.12)$ & $(1.89)$ & $(1.88)$ & $(2.15)$ & $(1.81)$ & $(1.97)$ \\
RED & 10.91 & 11.71 & 9.15 & 8.16 & 10.44 & 7.32 \\
& $(4.26)$ & $(3.94)$ & $(4.41)$ & $(4.22)$ & $(4.32)$ & $(3.87)$ \\
ROS & 40.07 & 44.91 & 29.53 & 25.00 & 36.57 & 20.76 \\
& $(29.31)$ & $(29.55)$ & $(25.86)$ & $(23.00)$ & $(28.23)$ & $(19.19)$ \\
RIN & 19027.84 & 20317.48 & 16215.78 & 14749.07 & 17748.45 & 13649.29 \\
& $(8938.52)$ & $(9087.66)$ & $(7925.92)$ & $(6962.73)$ & $(8568.46)$ & $(5935.35)$ \\
YB* & 28.44 & 27.18 & 31.20 & 30.90 & 27.35 & 32.21 \\
& $(11.34)$ & $(11.54)$ & $(10.40)$ & $(11.48)$ & $(13.30)$ & $(10.49)$ \\
\hline
\end{tabular}

* Year of Birth $=$ This variable was added in the regression analysis in order to control for age achievement differences. 
with about 14,700 IL. The same patterns reveal when comparing each ethnic group by type of communities; the AA's residing in the "center" have higher education, occupational status and annual income, as compared to those AA's residing in the "periphery". The same is true when comparing EA's residing in the "center" to those residing in the "periphery".

The same picture emerges when the status of origin variables are examined, and the means of father's education and occupational prestige for respondents residing in the "center" are considerably higher than for those residing in the "periphery" ( 2.77 and 35 respectively, as against 2.11 and 28 respectively). The same is true when comparing each ethnic group by type of community.

Let us now proceed to the main business at hand, namely the effect of the community on the structure of the status attainment process, in terms of its flexibility and openness. As was seen in the introduction, Hochbaum and Hodge have apparently been the first to relate systematically to the dimension of flexibility in the structure of status attainment, as reflected by the extent to which achieved components are "free" or independent of each other, or else "crystallized" or interdependent.

Applying this perspective to the data, we find indeed perceptible differences between "center" and "periphery". Table 2 shows the respective correlations between education, occupational status, and income in the two types community.

As may be seen, in the "center" the correlation between education and occupational pres-

TABLE 2 Correlations between achieved variables for employed males aged $25-64$ by types of settlements (Center vis a vis periphery)

\begin{tabular}{l|ccc}
\hline & \multicolumn{3}{|c}{ Center } \\
\hline Periphery & 1 & 2 & 3 \\
\hline (1) $\quad$ Respondent's education & - & .69 & .45 \\
(2) $\quad \begin{array}{l}\text { Respondent's occupational } \\
\text { status }\end{array}$ & & & \\
(3) $\quad$ Respondent's income & .64 & - & .50 \\
\hline
\end{tabular}

tige is 0.69 , and in the "periphery" 0.64 . The correlations between income and education, and between income and occupational prestige are in the earlier 0.45 and 0.50 respectively, and in the latter 0.53 and 0.60 respectively. The findings thus show that in the "central" communities, the nexus between educational and occupational attainment is somewhat higher. In respect to the other relationships, however the interdependence is perceptibly lower - signifying that in the "center" there exists a lower association between income and both education and occupational status as compared to the "periphery". On balance, therefore, in the more and diversified urban opportunity structure, attainment is less "crystallized" and more flexible.

The same picture is obtained when we go on to status attainment openness or universalism as used by Lane and defined by Treiman, and reflected in the extent to which respondent's occupational status is determined by respondent's own education as against his inherited status, in terms of father's occupation.

Table 3 presents selected metric regressions for the two populations - "central" and "peripheral" - of respondent's occupational status on his own educational attainment and his father's occupational prestige, and of respondent income on his own educational attainment and his occupational prestige (it should be mentioned here that father's occupational status has only a very small and insignificant effect on the income attainment in both communi. ties).

TABLE 3 Selected metric regression coefficients of occupational status and income attainment for the two communities: Employed males aged $25-64 \mathrm{~A}$

\begin{tabular}{|c|c|c|c|c|}
\hline & $\begin{array}{l}\text { Effect of } \\
\text { FOS on } \\
\text { ROC }\end{array}$ & $\begin{array}{l}\text { Effect of } \\
\text { RED on } \\
\text { ROC }\end{array}$ & $\begin{array}{l}\text { Effect of } \\
\text { ROC on } \\
\text { RIN }\end{array}$ & $\begin{array}{l}\text { Effect of } \\
\text { RED on } \\
\text { RIN }\end{array}$ \\
\hline \multirow[t]{2}{*}{ Center } & 0.049 & 4.178 & 100.878 & 412.286 \\
\hline & $(.004)^{\mathrm{B}}$ & $(.227)$ & $(14.311)$ & (101.823) \\
\hline \multirow[t]{2}{*}{ Periphery } & 0.207 & 3.349 & 138.800 & 263.006 \\
\hline & $(.076)$ & $(.341)$ & $(21.438)$ & $(127.560)$ \\
\hline
\end{tabular}

A All variables in our study were controlled in the regression equation: (FED, SIB, YB, CB).

B Standard errors in parenthesis. 
Clearly, the effect of respondent's educational attainment on his occupational status is greater in the "center" than in the "periphery" (4.178 vis. 3.349 respectively, this difference was found to be significant, $\mathrm{p}<.02)^{10}$; while father's occupa tional prestige has a large and significant effect on respondent's occupation only in the "periphery" ( 0.207 in the "periphery as opposed to 0.049 in the "center"; this difference was found to be significant, p. $<.01)$.

The effect of respondent's own education on his income is significantly higher in the "center" as compared to the effect of this variable in the "periphery" (412.286 vis. 263.006 respectively $\mathrm{p}<.001$ ). Respondent's own occupational status has somewhat higher effect on his income in the "periphery" as compared to the "center" (100.878 in the "center" vis. 138.800 in the "periphery").

As may thus be seen, Treiman's formulation originally aimed at comparing stratificational systems of nations at different level of development, holds also for Israel internally: in cities constituting the societal "center" in which the division of labor is more complex, the occupational scope and variety greater, and the opportunity in general better, status attainment is essentialy universalistically structured; while

10 The significance test used was the $T$ test between regression coefficients, expressed in the scales of original measured variables. That is:

$$
\mathrm{t}=\frac{\mathrm{B} 1-\mathrm{B} 2}{\mathrm{SD}}
$$

when:

B1 $=$ The regression coefficient in group 1.

$\mathrm{B} 2=$ The regression coefficient in group 2

$\mathrm{SD}=\left[\left(\frac{1}{\mathrm{~S}_{\mathrm{X} 1}}\right)+\left(\frac{1}{\mathrm{~S}_{\mathrm{x} 2}}\right)\right]$

$\left\{\frac{N_{1}+N_{2}-4}{\left[\left(\mathrm{SD}_{\left.\mathrm{y}_{1}\right)^{2}}-(\mathrm{B} 1)^{2}\left(\mathrm{~S}_{\mathrm{x} 1}\right)^{2}\right]-\left[\left(\mathrm{SD}_{\left.\left.\mathrm{y}_{2}\right)^{2}-(\mathrm{B} 2)^{2}\left(\mathrm{~S}_{\mathrm{x} 2}\right)^{2}\right]}\right]\right.\right.}\right.$

when:

$\mathrm{S}_{\mathrm{xi}}=$ The standard deviation of the independent variable in each of the two groups $\mathrm{i} ; \mathrm{i}=1,2$

$\mathrm{SD}_{\mathrm{yi}}=$ The standard deviation of the dependent variable in each of the two groups $\mathrm{i}=1,2$ in those in the "periphery", a more particular istic process prevails.

Ethnic discrimination in level of attainment as a function of community residence

The procedure used for determining the extent of non-additive racial discrimination is similar to that used by Adler/Hodge (1976). In order to obtain the effect of ethnicity which cannot be explained by their differences in resources on each of the achieved status variables, we have calculated the regression equation of each of the achieved variables as a function of the antecedent variables in each of the two community configurations (i.e. "periphery" and "center"). The estimated structural equations for the "periphery" are presented below, expressed in the scales of original measured variables rather than in standardized form, as follows:

$$
\begin{aligned}
\text { Eq. la: } \widehat{\operatorname{ROS}=} & +0.3698-1.0391\left(\mathrm{FED}_{\mathrm{i}}\right)+ \\
& .2070\left(\mathrm{FOS}_{\mathrm{i}}\right)-.8691\left(\mathrm{SIB}_{\mathfrak{i}}\right) \\
& -.0779\left(\mathrm{YB}_{\mathrm{i}}\right)+3.3494\left(\mathrm{RED}_{\mathrm{i}}\right) \\
& +2.5510\left(\mathrm{CB}_{\mathrm{i}}\right) \\
\text { Eq. 1b: } \widehat{\mathrm{RIN}}= & 3633.0137+287.1092\left(\mathrm{FED}_{\mathrm{i}}\right) \\
& +.0001\left(\mathrm{FOS}_{\mathfrak{i}}\right)+394.7729 \\
& \left(\mathrm{SIB}_{\mathfrak{i}}\right)+75.1105\left(\mathrm{YB}_{\mathrm{i}}\right)+ \\
& 138.8001\left(\mathrm{ROS}_{\mathrm{i}}\right)+2053.1429 \\
& \left(\mathrm{CB}_{\mathrm{i}}\right)
\end{aligned}
$$

The basis for the decomposition of ethnic differentials in the "periphery" rests upon the properties of these equations. It can be shown that $\mathrm{Eq}$. la and Eq. $1 \mathrm{~b}$ must pass through the withingroup means for both European-Americans and for Asian-Africans in the "periphery", and we therefore obtain from Eq. la that

$$
\text { Eq. } \begin{aligned}
2 \mathrm{a}: \overline{\operatorname{ROS}}_{\mathrm{e}}= & 2.9208-1.0391 \overline{\left(\overline{\mathrm{FED}_{\mathrm{e}}}\right)+} \\
& .2 .070\left(\overline{\left.\mathrm{FOS}_{\mathrm{e}}\right)}-.8691 \overline{\left(\mathrm{SIB}_{\mathrm{e}}\right)}\right. \\
& -.0779 \overline{\left(\mathrm{YB}_{\mathrm{e}}\right)}+3.394\left(\overline{\left(\mathrm{RED}_{\mathrm{e}}\right)}\right.
\end{aligned}
$$

where the subscripted " $\mathrm{e}$ " refers to the within group mean for European-Americans. The constant term in this equation is given by the sum of the constant term in Eq. la $(=0.3698)$ plus the coefficient of $\mathrm{CB}_{\mathrm{i}}$ in $\mathrm{Eq}$. la $(=2.5510)$, since for European-American $\mathrm{CB}=1$ we also obtain from Eq. la that

$$
\text { Eq. } \begin{aligned}
2 \mathrm{a}^{\prime}: \overline{\mathrm{ROS}}_{\mathrm{a}}= & 0.3698-1.0391\left(\overline{\mathrm{FED}}_{\mathrm{a}}\right)+ \\
& .2070\left(\overline{\mathrm{FOS}}_{\mathrm{a}}\right)-.8691\left(\overline{\mathrm{SIB}_{\mathrm{a}}}\right) \\
& -.0779\left(\overline{\mathrm{YB}}_{\mathrm{a}}\right)+3.3494\left(\overline{\mathrm{RED}}_{\mathrm{a}}\right)
\end{aligned}
$$


where the subscripted "a" denotes a within group mean for Asian-Africans. The constant term is the same in Eq. $2 a^{\prime}$ as in Eq. la since $\mathrm{CaB}=0$ for those of African-Asian origin.

When we subtract Eq. 2a from Eq 2a', we obtain the decomposition of ethnic differences in occupational status in the periphery,

$$
\begin{aligned}
\overrightarrow{\mathrm{ROS}}_{\mathrm{e}}-\overline{\mathrm{ROS}}_{\mathrm{a}}=- & 1.0391(\overline{\mathrm{FED}} \mathrm{e}-\overline{\mathrm{FED}} \mathrm{a})+ \\
& 2.070(\overline{\mathrm{FOS}}-\overline{\mathrm{FOS}})- \\
& .8691(\overline{\mathrm{SIBe}}-\overline{\mathrm{SIBa}})- \\
& .0779(\overline{\mathrm{YB}} \mathrm{e}-\overline{\mathrm{YB}} \mathrm{a})+ \\
& 3.3494(\overline{\mathrm{RED}} \mathrm{e}-\overline{\mathrm{RED}} \mathrm{a})+ \\
& 2.5510
\end{aligned}
$$

This decomposition divides the gross difference between ethnic groups in the "periphery" in occupational status, into six parts:

\section{(1) $-1.0391(\overline{\text { FED }}-\overline{\text { FEDa }})=$} difference in the composition of the ethnic groups with respect of father's education.

(2) $.2070(\overline{\mathrm{FOS}} \mathrm{e}-\overline{\mathrm{FOSa}})=$ difference in the composition of the ethnic groups with respect of father's occupational status.

$-.8691(\overline{\mathrm{SIB} e}-\overline{\mathrm{SIB}} \mathrm{a})=$ difference in the composition of the ethnic groups with respect to number of siblings.

$-.0779(\overline{\mathrm{YB}} \mathrm{e}-\overline{\mathrm{YB}} \mathrm{a})=$ difference in the composition of ethnic groups with respect to year of birth.

(5) $3.3494(\overline{\mathrm{RED}} \mathrm{e}-\overline{\mathrm{RED}} \mathrm{a})=$ difference in the composition of ethnic groups with respect to respondent's education.

\section{(6) 2.5510}

which represents a net difference between the occupational status of the two groups in the "periphery", which cannot be explained away by either of the variables in the equation. This net difference represents thus the amount of discrimination between the European-American born and the Asian-Africans on occupational status achievement in the "periphery", so that the greater the net difference, the greater is the discrimination.

Using the same procedure, we have computed the amount of the net differences between the occupational status of the two groups also for
TABLE 4 Net differences in percent, out of the total difference between Asian-Africans and EuropeanAmericans in occupational status and income for the two communities: Employed males aged 25-64

\begin{tabular}{lcc}
\hline & Occupational Status & Income \\
\hline Center & $5 \%$ & $8 \%$ \\
Periphery & $15 \%$ & $31 \%$ \\
\hline
\end{tabular}

the "center", and Table 4 presents the net differences in occupational status achievement in the two community types.

We can see that the percentage of the net difference in occupational status between the two groups out of the total difference is higher in the "periphery" than in the "center" (15\% as against $5 \%$ ). When computing from Table 4 the same net differences in income level using the same procedure, we can see that the percentage of the net differences in income level between the two groups out of the total differences is also higher in the "periphery" than in the "center" (31\% as against $8 \%)$.

It can thus be seen that, as expected and as found in previous studies in respect to additive effects, type of community of residence influences ethnic discrimination: in the "central" communities, representing a better and more diversified socio-economic opportunity structure, the amount of this discrimination is significantly lower than in the "peripheral" ones.

\section{Ethno-ecological status attainment patterns}

In the preceding sections we have shown that there exists in "central" and "peripheral" communities in Israel a differential process of status attainment; and that there are also distinctions in the rate of ethnic discrimination characteristics of the two community types. Namely, we have documented that attainment in the "center" is generally higher and more flexible and open, as well as ethnically less discriminatory; and in the "periphery" its level is lower, its structure more "crystallized" and particularistic, and its rate of ethnic discrimination greater - so that the "low" ethnics residing in the former are more likely to narrow the stratifica- 
tional gap, and those in the latter to widen it further. The purpose of the analysis that follows is to see whether within this overall process there develop specific ethno-ecological patterns of attainment, representing the interaction of ethnicity and community and reflecting a differential adjustment to and way of coping with specific opportunity structure effects.

Taking the two structural status attainment variables of flexibility and openness, represented respectively by the degree of "crystallization" of achieved status variables, and by the extent of independence of inherited and achived status - we thus analyze four populations: Europe and America born - EA's - in "center" and "periphery", and Asia-Africa born - AA's - in "center" and "periphery".

TABLE 5a Correlations between achieved and inherited variables for employed males aged 25-64 residing in the "periphery" by ethnic groups.

\begin{tabular}{l|rrrrrr}
\hline & \multicolumn{5}{|c}{$\begin{array}{l}\text { AA } \\
\text { born }\end{array}$} \\
\cline { 2 - 7 } $\begin{array}{l}\text { EA } \\
\text { born }\end{array}$ & FED & FOC & SIB & RED & ROC & RIN \\
\hline FED & - & .40 & .08 & .23 & .16 & .18 \\
FOC & .52 & - & .01 & .07 & .17 & .04 \\
SIB & .20 & -.13 & - & .16 & .02 & .19 \\
RED & .43 & .24 & -.28 & - & .52 & .40 \\
ROC & .26 & .32 & -.22 & .74 & - & .48 \\
RIN & .24 & .27 & -.09 & .65 & .68 & - \\
\hline
\end{tabular}

TABLE 5b Correlations between achieved and inherited variables for employed males aged 25-64 residing in the "center" by ethnic groups

\begin{tabular}{l|rrrrrr}
\hline & \multicolumn{5}{|c}{$\begin{array}{l}\text { AA } \\
\text { born }\end{array}$} \\
\cline { 2 - 7 } $\begin{array}{l}\text { EA } \\
\text { born }\end{array}$ & FED & FOC & SIB & RED & ROC & RIN \\
\hline FED & - & .38 & -.03 & .43 & .36 & .36 \\
FOC & .66 & - & -.01 & .25 & .19 & .15 \\
SIB & -.21 & -.14 & - & .06 & -.03 & -.08 \\
RED & .40 & .32 & -.28 & - & .67 & .55 \\
ROC & .40 & .32 & -.29 & .67 & - & .58 \\
RIN & .18 & .24 & -.22 & .37 & .44 & - \\
\hline
\end{tabular}

As may be seen, the association between respondent's income, education and occupational status is highest among EA's residing in the "periphery" (the correlation between income and education is here .65 and between income and occupational status .68), while a somewhat lower association - but still high - characterizes AA's residing in the "center" (the correlation between income and education and income and occupational prestige being here .55 and .58 respectively). And conversely - among EA's residing in the "center" and among AA's residing in the "periphery", the correlations are generally much lower, though slightly higher for the earlier (being .40 and .48 between income and education and between income and occupational prestige in the one population, and .37 and .44 in the second). A similar although less sharp pattern of association is obtained between occupational prestige and education: it is highest among "peripheral" EA's (.74) and lowest among "peripheral" AA's (.52) while among those residing in the "center" the correlation is the same (.67).

It should be mentioned that the correlations between inherited variables (father's education, father's occupational prestige) and the achieved variables (respondent's education, occupational prestige and income) are significantly higher in the AA's ethnic group residing in the "center" as compared to AA's residing in the "periphery".

Comparing these correlations (inherited with achieved) between EA's by type of communities shows no significant differences. (For purpose of comparison Appendix A describes the overall correlations between these variables by ethnic groups for employed males aged $25-64$ in Israel.)

Taken together, these correlations thus consistently show that status "crystallization" is higher - that is, attainment flexibility is lower - in the structure of attainment of EA's in the communities characterized by a less advantageous opportunity structure, and in the structure of attainment of AA's in the more advantageous ones; and conversely. In other words, among the EA's the "peripheral" group is less flexible, and the "central" one more, and the reverse is true of the AA's. That is to say, the status attain- 
TABLE 6 Metric coefficients of occupational status and income for employed males aged 25-65 by ethnic groups and types of community. ${ }^{\mathrm{a}}$

\begin{tabular}{|c|c|c|c|c|c|c|c|c|}
\hline \multirow{3}{*}{$\begin{array}{l}\text { Independent } \\
\text { Variables }\end{array}$} & \multicolumn{4}{|c|}{ CENTER } & \multicolumn{4}{|c|}{ PERIPHERY } \\
\hline & \multicolumn{2}{|c|}{ European-American } & \multicolumn{2}{|c|}{ Asian-African } & \multicolumn{2}{|c|}{ European-A merican } & \multicolumn{2}{|c|}{ Asian-African } \\
\hline & ROC & RIN & ROC & RIN & ROC & RIN & ROC & RIN \\
\hline FED & $\begin{array}{c}2.398 \\
(1.031)\end{array}$ & $\begin{array}{c}-696.547 \\
(388.100)\end{array}$ & $\begin{array}{c}2.080 \\
(1.394)\end{array}$ & $\begin{array}{c}942.674 \\
(476.369)\end{array}$ & $\begin{array}{c}-3.748 \\
(2.328)\end{array}$ & $\begin{array}{c}-329.578 \\
(778.083)\end{array}$ & - & $\begin{array}{c}426.1 \\
(475.3)\end{array}$ \\
\hline FOC & $\begin{array}{c}0.058 \\
(0.056)\end{array}$ & $\begin{array}{c}53.161 \\
(20.969)\end{array}$ & - & $\begin{array}{c}-15.542 \\
(24.556)\end{array}$ & $\begin{array}{c}0.293 \\
(0.138)\end{array}$ & $\begin{array}{c}32.475 \\
(46.938)\end{array}$ & $\begin{array}{c}0.147 \\
(0.082)\end{array}$ & $\begin{array}{c}-10.0 \\
(27.7)\end{array}$ \\
\hline SIB & $\begin{array}{c}-1.654 \\
(0.607)\end{array}$ & $\begin{array}{c}-637.617 \\
(229.199)\end{array}$ & $\begin{array}{c}-0.832 \\
(0.725)\end{array}$ & $\begin{array}{c}-341.180 \\
(234.978)\end{array}$ & $\begin{array}{c}-0.325 \\
(1.541)\end{array}$ & $\begin{array}{c}545.431 \\
(502.358)\end{array}$ & $\begin{array}{c}-0.590 \\
(0.689)\end{array}$ & $\begin{array}{r}408.5 \\
(211.2)\end{array}$ \\
\hline RED & $\begin{array}{c}4.441 \\
(0.295)\end{array}$ & $\begin{array}{r}299.664 \\
(135.754)\end{array}$ & $\begin{array}{c}3.749 \\
(0.352)\end{array}$ & $\begin{array}{c}500.482 \\
(143.291)\end{array}$ & $\begin{array}{c}4.966 \\
(0.695)\end{array}$ & $\begin{array}{c}744.754 \\
(323.445)\end{array}$ & $\begin{array}{c}2.697 \\
(0.385)\end{array}$ & $\begin{array}{c}133.9 \\
(137.2)\end{array}$ \\
\hline ROC & & $\begin{array}{c}100.411 \\
(17.820)\end{array}$ & & $\begin{array}{l}108.237 \\
(22.834)\end{array}$ & & $\begin{array}{l}124.427 \\
(46.535)\end{array}$ & & $\begin{array}{c}125.7 \\
(25.7)\end{array}$ \\
\hline
\end{tabular}

a. Year of Birth was controlled in the regression equation

b. Standard errors in parantheses.

ment structure of the EA's is more flexible or less "crystallized" where its urban setting is more developed and diversified; and more rigid where the opposite is the case; among the AA's by contrast, structural interdependence of status attainment components manifests itself more in the first situation, and less in the second.

Let us now move to the second dimension that of attainment openness or universalism through regressions which calculate the way respondent's occupational status and income re. lated to his own education, and to his father's occupational status ${ }^{11}$. Table 6 compares the four regression equations for the four ethno-re-

11 We tried to include interaction terms between the antecedent variables, in the structural equations, in order to examine whether there exists a nonadditive model. Those interaction terms have been found to have a very high correlation with the other variables in the model (arround .90 and higher). Those high correlations between the interaction terms and the other variables in the model emerge also when analysing each ethnic group separately. High correlations among the interaction terms and the other variables in the model, lead to imprecise coefficent estimates and to high correlations among the estimated coefficients.

These results of multicollinearity can seriously handicap our ability to make inferences about individual coefficients; because of the multicollinearity we decided not to include the interaction terms in the model. sidential groups, showing that the effect of respondent's own educational attainment among the EA's is higher in the "periphery" (4.966) than in the "center" $(4.441, \mathrm{p}<.10)$, while among the AA's it is higher in the "center" (3.749) and lower in the "periphery" (2.697 only, $\mathrm{p}<001$ ). The same results reveal when examining the income attainment. The effect of respondent's own education attainment among the EA's in the "periphery" is 744.754 and among the same group residing in the "center" it is 299.664 ( $p<.001$ ), the effect of education attainment among the AA's in the "center" on income is 500.482 while the effect of this variable among AA's residing in the "periphery" is only $113.994(p<.001)$. As regards the impact of father's occupational status on respondent's occupational status, for EA's residing in the "periphery" it is higher comparing to AA's residing in the same type of community $(0.293$ as 0.147 respectively, $p<.001)$, while in the "center" it has no impact in either group (the impact of father's occupational status on income in the four ethno-residential groups is sunall and insignificant).

It should be mentioned that the effect of respondent's own occupational status on income attainment is almost the same among the four groups. 
We can thus conclude that there emerge indeed, as suggested, specific ethno-ecological or ethnoresidential attainment patterns; in other words, each ethnic community reacts differentially to each urban community - both groups having different attainment processes, in terms of flexibility and universalism, in different types of opportunity structure. These differences are in fact greater than the ethnic ones alone: in this way, while the general difference between EA's and AA's in educational pay-off to occupational attainment is 1.688 , the difference between "central" and "peripheral" EA's in this respect is -.525 , and between "central" and "peripheral" AA's 1.052. And a similar situation obtains in respect to the relationship between occupational attainment and father's occupation: here the difference between the two ethnic groups is -.0541 , between "central" and "peripheral" EA's - .235, and between "central" and "peripheral" AA's - 147 .

\section{Discussion}

In trying to evaluate the analysis presented, two distinct though related issues stand out: the appropriateness and reproductibility of the research strategy, or of the conceptualization of the urban opportunity structure; and the significance and generality of the findings. Let us take up each of these issues in turn.

If the proof of the pudding is in the eating, then the strategy adopted for defining communities of residence so as to observe their effect on status attainment process, has certainly been successful. At least, it has been successful as far as the dependent variable - i.e., status attainment - is concerned; and combining community types on the basis of a series of generalized urban geodemographic properties has indeed allowed us to identify and examine clear cut and significant differences in the resident's status attainment, in terms of level of achievement, as well as the structure of the process. Nor should there be any difficulty in transferring this strategy and of adapting it technically to other settings, by appropriately adjusting the categories. In this way, values for size and age will change; social composition may embody different criteria in non-immigrant societies, or combine with others; while in countries less miniscule than
Israel, location may refer to cities within a region, and then to regions themselves - such as North and South in the U.S.A. (as is in fact being done in an ongoing study in Brazil, in which cities are classified or scored relative to their regional centrality, and as regards their region's relative centrality in the overall national system - Shahar, forthcoming). More problematic is the question of the actual suitability and utility of this approach in settings which are more homogeneous than Israel. That is: in which the population itself is less sharply polarized (as is indeed the situation in the U.S.A.; for though race may be more "primordial" and visible than ethnicity, the fact is that the issue there is much less numerically salient and that the black minority is native born; while in Israel the society is dual, almost evenly split in two, and "low" ethnicity also overlaps with a different socio-cultural background, and a lower developmental level). And/or in which the communities are less sharply distinct than in Israel (where some types, as development towns, are institutionally defined and newly established from above) and in which, again as in the United States, structural urban profiles may in fact be more similar to each other and only very partially ordered. However, it seems that it is precisely in situations of greater homogeneity that comparing structurally defined urban profiles may be most indicated. For, the greater the homogeneity, and the smaller the differences in status attainment to be identified, the greater seems to be the need for community types that are broadly defined and which encapsulate extreme varia. tions. Not so, though, as far as the price that this conceptualization entails in terms of precision and urban theory. For while the use of geodemographic criteria is certainly easier, lends itself well to comparative studies, and seems appropriate for observing the stratificational end product - it does not serve the end of defining and tracing actual opportunity structure mechanisms as formulated by Treiman, and of evaluating their respective impact under different conditions. A "proper" solution might lie in combining the two - that is, first employing structural community profiles, and through them identifying significant attainment patterns; and then disaggregating these profiles into their constituent opportunity structure components, and analyzing them. In this way, the extent to which the basic assumption that structural profiles re- 
present well variations in opportunity structure, will also be empirically tested.

Going on to the findings themselves, it appears that the part of the analysis in which the structure of attainment and ethnic discrimination are analyzed presents a clear and unambiguous picture. First of all, as far as Israel is concerned, the data are significant, consistent, and in line with earlier studies - and it thus can now be definitively said that, in this country at least, community of residence exercises both an additive and a non-additive effect on general and ethnic stratification. That is to say, the more "central" the community, the higher its level of attainment, the more flexible and universalistic its attainment process, and the lesser its ethnic discrimination. Second, albeit to a lesser extent of course, the data presented have also a wider significance. To be sure, it cannot be said that the Israeli findings resolve the American controversy, although they certainly lend support to the ayes. These findings, however, suggest a general formulation, to wit - that in societies in which stratificational processes are not uniform, different types or profiles of community of residence will reflect and mediate these differences; and the greater the social and the urban heterogeneity in this respect, the greater will be the net community effect.

The last section of the analysis, presenting findings on the formation of ethno-ecological patterns of status attainment, seems more novel and interesting, but it is also more difficult to interpret and generalize from.

By and large, the findings show a consistent pattern of differences in the status attainment structures of the four populations studied Asia-Africa born and Europe-America born in the "center", and Asia-Africa born and EuropeAmerica born in the "periphery". These differences, moreover, relate to both aspects examined: the "crystallization" of status dimensions, reflecting extent of general flexibility of the attainment process; and the weight of own resources in the attainment of occupational status components as against inherited ones, and reflecting extent of openness or universalism. From the pattern observed it is thus clear that there is indeed a significant division along ethnoecological lines, to wit: among the Europe and American born, the process of attainment is more flexible and open in the "center" and more crystallized and particularistic in the "petiphery"; while among the Asia-Africa born, the reverse is true. Less clear, from the data, though, is why does the observed ethno-ecological differentiation in attainment actually operate. One explanation, in line with the other findings, is the differential ethnic discrimination in the two community types. In the "periphery", as we have seen, the liability of "low" ethnicity and the pay-off for "high" ethnicity are greater. Therefore, the AA's fit here into the situation better by being more flexible and universalistic, while the EA's receive a greater premium through a crystallized and a particularistic attainment structure. In the "center", by contrast, the ethnic differential is smaller, and a reverse balance therefore constitutes a better utilization of the opportunity structure. That is to say, in their differential structure of attainment, the two groups adjust to objectively different ethno-residential opportunity structures. The difference, in other words, lies not in the intrinsic attainment characteristics themselves, but in the differential situations in which the two groups find themselves, and which promote different "mixes" of inherited and achieved status. Or, the findings can be attributed rather to ethnic contents, and in particular to different levels of modernity in the two origin groups, which impinge on their status attainment models proper. Namely - the attainment structure of the "pre-modern" Oriental groups can be relatively less crystallized, and more flexible and open in a small, largely ethnic community, constituting a situation which is familiar and "controlled", less developed and challenging, and in which the community is in a large measure the extension of the "traditional" way of life; but less so in a setting which is impersonal, and more developed and competitive, and in which this group is thrown more upon itself. Such an interpretation, though apparently paradoxical, is in line with evidence obtained in other settings in Israel, namely in new smallholders' cooperative villages settled by similar traditional immigrants. In this way, Weintraub/ Bernstein (1965) found that it was the stronger and more "organic" traditional Oriental social structure, which was better able to facilitate modernization through social consensus and security: its assured core of genuine loyalty and support allowed it, as it were, to "unfreeze" or release parts of the commitment to tradition. In other words, the status attainment models 
analyzed reflect levels of modernity and are part and parcel of the general process of modernization in which individual, group and milieu interact. We ourselves think that both mechanisms in fact operate and interact here, in particular among the AA's; and that the status attainment processes identified represent thus functional adjustment together with socio-cultural factors. However, even if this is so, we may speculate that the findings obtained have differential generality and relevance to other settings: while the mechanism of adjustment to varying primordial discrimination in different community types may well be universal, the sociocultural mechanism is likely to apply only to groups whose status attainment takes place in a context of rapid pronounced social change and modernization. That is to say, one may expect to find it primarily at specific crossroads or junctions of time; and the Israeli situation may therefore well be rare, and relevant only to such other groups as West Indian or Pakistani migrants in Britain - and even there to a les-

\section{References:}

Adler, Israel/Hodge, Robert R.W., 1976: Ethnicity and the process of status attainment in Israel (mimeo). Jerusalem: Department of Sociology, The Hebrew University.

Berler, Alexander, 1970: New Towns in Israel. Jerusalem: Israel Universities Press.

Blau, Peter M./Duncan, Otis D., 1967: The American Occupational Structure. New York: Wiley.

Cohen, Erik, 1969: Population Dispersion and Immigrant Absorption as Conflicting Objectives (Symposium on the Integration of Immigrants in Israel). Jerusalem: Hebrew University (in Hebrew).

Duncan, Otis Dudley/Reies, Albert A.J., 1956: Social Characteristics of Urban and Rural Communities, 1950. New York: Wiley.

Eisenstadt, Shmuel N., 1953: Absorption of Immigrants. London: Routledge and Kegan Paul.

Eisenstadt, Shmuel N., 1956: Sociological aspects of the economic adaptation of Oriental immigrants in Israel: A case study in the process of modernization. Economic Development and Cultural change IV, 3.

Eisenstadt, Shmuel N., 1967: Israel Society. London: Weidenfeld and Nicholson.

Hodge, Robert W./Siegel, Paul M., 1968: The measurement of social class. Pp. $316-325$ in: D. Sills (ed.), International Encyclopaedia of the Social Sciences, Vol. 15. New York: The MacMillan Company and The Free Press. ser extent. However, to relate to this issue properly, further and comparative research is of course necessary.

\section{Appendix A}

Correlations between achieved and inherited variables for employed males aged $25-64$ by ethnic groups in Israel.

\begin{tabular}{l|rrrrrr}
\hline & \multicolumn{6}{|c}{$\begin{array}{l}\text { AA } \\
\text { born }\end{array}$} \\
\cline { 2 - 7 } $\begin{array}{l}\text { EA } \\
\text { born }\end{array}$ & FED & FOC & SIB & RED & ROC & RIN \\
\hline FED & - & .40 & -.11 & .35 & .25 & .14 \\
FOC & .58 & - & -.04 & .17 & .18 & .06 \\
SIB & -.22 & -.13 & - & -.02 & -.03 & -.01 \\
RED & .41 & .31 & -.32 & - & .50 & .28 \\
ROC & .35 & .28 & -.26 & .65 & - & .22 \\
RIN & .15 & .13 & -.16 & .25 & .25 & - \\
\hline
\end{tabular}

Hodge, Robert W., 1970: Social integration, psychological well-being and their socio-economic correlates. Pp. 182-206 in: E.D. Lauman (ed.), Social Strat If ication: Research and Theory for the 1970 's. Indianapolis: Bobbs-Merrill.

Hochbaum, Godfrey/Darley, John/Monachesi, E./Bird, Charles, 1955: Socio-economic variables in a large city. American Journal of Sociology 61 (July): $31-38$.

Hauser, Robert M./Featherman, David L., 1977: Socioeconomic achievements and city size. Pp. 249 -267 in: The Process of Stratification. New York: Academic Press.

Kraus, Vered, 1976: Social Grading of Occupations. Unpublished Ph. D. Thesis. Jerusalem: The Hebrew University.

Lane, Angela, 1968: Occupational mobility in six cities. American Sociological Review 33 (October): $740-749$.

Lane, Angela, 1972: Contexts of socio-economic attainment: the role of community, industry of employment and spatial mobility. Unpublished doctoral dissertation. Chicago: University of Chicago.

Lissak, Moshe, 1963: Tendencies in Occupational Choice of Israeli Urban Youth. Unpublished Ph. D. Thesis. Jerusalem: The Hebrew University (in Hebrew).

Lissak, Moshe, 1969: Social Mobility in Israeli Society. Jerusalem: Israel Universities Press. 
Matras, Judah, 1962: Israel: Absorption of Immigrants, Social Stability and Social Changes. Unpublished Ph. D. Thesis. Chicago: University of Chicago.

Matras, Judah, 1965: Social Change in Israel. Chicago: Aldine.

Matras, Judah/Weintraub, Dov, 1977a: Ethnic and Other Primordial Differentials in Israel. Discussion Paper. Jerusalem: Brookdale Institute.

Matras, Judah/Weintraub, Dov, 1977b: Center-Periphery Differentials in Intergenerational Mobility in Israel. Discussion Paper. Jerusalem: Institute of Urban and Regional Studies, The Hebrew University.

Mueller, Charles W., 1974: City effects on socio-economic achievements: the case of large cities. American Sociological Review 39.

Rogoff, Natalie, 1957: Recent trends in occupational mobility. In: Paul H. Halt et al. (eds.), Cities and Society. Glencoe, Illinois: The Free Press.

Rossi, Peter, 1972: Community social indicators. Pp. 87-126 in: A. Campbell/P. Converse (eds.), The Human Meaning of Social Change. New York: Russel Sage Foundation.

Schnore, Leo, 1963: The socio-economic status of cities and suburbs. American Sociological Review 28 (February): $76-85$.

Schnore, Leo/Varley, David, Some concomitants of metropolitan size. American Sociological Review 20 (August): $408-414$.
Shahar, Arie, forthcoming: Urbanization processes in Brazil. In: S.N. Eisenstadt/R. Cahane (eds.), Proceedings, Conference on Development and Urbanization in Latin America. Jerusalem: The Truman Institute, The Hebrew University.

Shahar, Arie/Weintraub, Dov/Shelah, Ilana/Cohen, Erik, (eds.), 1973: Town and City in Israel - A Reader. Jerusalem: Akedemon Press (in Hebrew).

Spilerman, Seymour/Habib, Jack, 1976: Development towns in Israel: The role of community in creating ethnic disparity in labor force characteristics. American Journal of Sociology 81 (January): 781 812.

Treiman, Donald J., 1970: Industrialization and social stratification. Pp. 207-234 in: Edward D. Laumann (ed.), Social Stratification: Research and Theory for the 1970's. Indianapolis: Bobbs-Merrill.

Thernstrom, Stephen, 1964: Poverty and Progress: Social Mobility in a Nineteenth Century City. Cambridge, Massachusetts: Harvard University Press.

Weintraub, Dov, 1965: A study of new farmers in Israel. Sociologia Ruralis IV: 1-49.

Weintraub, Dov/Kraus, Vered, 1977: Social Differentiation and Locality of Residance: Spatial Distribution, Composition and Stratification in Israel. Conference of I.S.A. Committee on Social Stratification and Mobility. Dublin, April. 